\title{
Changes Caused by Fruit Extracts in the Lipid Phase of Biological and Model Membranes
}

\author{
Dorota Bonarska-Kujawa $\cdot$ Hanna Pruchnik • \\ Jan Oszmiański • Janusz Sarapuk • \\ Halina Kleszczyńska
}

Published online: 3 September 2010

(C) The Author(s) 2010. This article is published with open access at Springerlink.com

\begin{abstract}
The aim of the study was to determine changes incurred by polyphenolic compounds from selected fruits in the lipid phase of the erythrocyte membrane, in liposomes formed of erythrocyte lipids and phosphatidylcholine liposomes. In particular, the effect of extracts from apple, chokeberry, and strawberry on the red blood cell morphology, on packing order in the lipid hydrophilic phase, on fluidity of the hydrophobic phase, as well as on the temperature of phase transition in DPPC liposomes was studied. In the erythrocyte population, the proportions of echinocytes increased due to incorporation of polyphenolic compounds. Fluorimetry with a laurdan probe indicated increased packing density in the hydrophilic phase of the membrane in presence of polyphenolic extracts, the highest effect being observed for the apple extract. Using the fluorescence probes DPH and TMA-DPH, no effect was noted inside the hydrophobic phase of the membrane, as the lipid bilayer fluidity was not modified. The polyphenolic extracts slightly lowered the phase transition temperature of phosphatidylcholine liposomes. The studies have shown that the phenolic compounds contained in the extracts
\end{abstract}

This work was sponsored by the Ministry of Science and Education, scientific project no NN305 337034.

D. Bonarska-Kujawa $(\bowtie) \cdot H$. Pruchnik $\cdot$ J. Sarapuk

H. Kleszczyńska

Department of Physics and Biophysics,

Wrocław University of Environmental and Life Sciences,

Norwida 25,

50-375 Wrocław, Poland

e-mail: dorota.bonarska-kujawa@up.wroc.pl

J. Oszmiański

Department of Fruit and Vegetable Technology,

Wrocław University of Environmental and Life Sciences,

Norwida 25

50-375 Wrocław, Poland incorporate into the outer region of the erythrocyte membrane, affecting its shape and lipid packing order, which is reflected in the increasing number of echinocytes. The compounds also penetrate the outer part of the external lipid layer of liposomes formed of natural and DPPC lipids, changing its packing order.

Keywords Anisotropy DSC · Erythrocyte lipids .

Generalized polarization $\cdot$ Liposomes $\cdot$ Phase transition

\section{Introduction}

Phenolic compounds contained in plant extracts are nowadays extensively studied because they exhibit many beneficial effects on living organisms, mostly due to their antioxidant properties. ${ }^{1,2}$ They are very good for scavenging free radicals, also those occurring as the reactive forms of oxygen. The reactive forms of oxygen, toxic for biological systems, are created within living organisms in metabolic reactions, whereas the external hazard for organisms derives from free radicals present in the environment, where they are induced, among others, by the electromagnetic radiation. High concentration of free radicals within an organism, caused by deficient function of the natural protective mechanisms, leads to oxidative stress that may cause multiple damages at the molecular and cell levels and result in many serious diseases. The damages, connected with oxidation of aminoacids, proteins, lipids, bases, and nucleic acids, as well as sugars, disturb the proper action of an organism. An exposed and very important place for attack by free radicals is the biological membrane since it is a place of first contact with cells. Membrane lipid oxidation by free radicals disturbs the structure and impairs function of the biological membrane, 
resulting in pathological changes within the organism. ${ }^{1}$ Incorporation of polyphenolic compounds into cell membranes prevents, at least partially, this oxidation and its consequences.

The attainment of an effective protection against membrane oxidation by means of phenolic compounds seems to depend on their ability to incorporate into biological membranes. ${ }^{3-5}$ Due to the lipophilic character of polyphenols, they are expected to interact mainly with the lipid phase of the biological membrane. The antioxidant activity of plant extracts, and specific compounds contained in them, has been documented in a very large number of studies conducted throughout the world. ${ }^{2,6-12}$ However, the mechanism of the protective action of natural antioxidants on organisms at the molecular and cell level has not yet been explained. There are few papers on the effect of plant extracts and polyphenol compounds on biological structures, biological and model membranes in particular. ${ }^{5,12-17}$ Polyphenols, when embedded in a membrane, modify the fluidity of its lipid phase to an extent depending on their depth of incorporation. $4,5,15,16,18$ The investigations have also revealed an antihemolytic effect of phenolic compounds on erythrocytes. ${ }^{15,19}$

As shown in other studies, polyphenolic substances contained in the extracts from apple, chokeberry, and strawberry, aside of the antioxidative, possess also many therapeutic properties. Among these: antimutagenic and antileukaemic activities reduce overall cholesterol and its LDL fraction, and enhance reduction in cardiovascular risk markers in patients after mycocardial infraction. ${ }^{20-23}$

The investigations reported here are concerned with changes in the properties of the lipid phase of the biological membrane (erythrocytes) and model lipid membranes (liposomes) induced by extracts from apple, chokeberry, and strawberry, with reference to their location within the membrane. Such studies, aiming at explaining the mechanism of the interaction between the extracts and a biological system at the molecular and cell levels were not conducted before.

\section{Materials and Methods}

The extracts from apple, chokeberry, and strawberry used in the investigation were obtained from the Fruit and Vegetable Department of Wrocław University of Environmental and Life Sciences. Polyphenols were isolated from fruits of chokeberry (Aronia melanocarpa E), apple (var. Idared), and strawberry (var. Senga Sengana) by extraction with water containing $200 \mathrm{ppm}$ of $\mathrm{SO}_{2}$, the ratio of solvent to fruits being 3: 1 . The extract was adsorbed on Purolite AP 400 resin (UK) for further purification. The polyphenols were then eluted out with $80 \%$ ethanol, concentrated and freeze-dried. By means of the above method, the mixture of polyphenols was obtained. ${ }^{20}$ The polyphenol composition was determined by means of the liquid chromatography HPLC-DAD, Merck-Hitachi L-7455 $5^{9,10,12}$ (Table 1).

The fluorescent probes 6-dodecanoyl-2-dimethylaminonaphthalene (laurdan), 1,6-diphenyl-1,3,5-hexatriene (DPH), 1-(4-trimethylammoniumphenyl)-6-phenyl-1,3,5hexatriene $\mathrm{p}$-toluenesulfonate (TMA-DPH) were purchased from Molecular Probes, Eugene, Oregon USA.

The lipids 1,2-dipalmitoyl-sn-glycero-3-phosphatidylcholine (DPPC) and L- $\alpha$-phosphatidylcholine from egg yolk (egg-PC) were purchased from Sigma Aldrich, Steinheim, Germany. Natural lipids were extracted from erythrocyte membranes according to the method described in Maddy et al. $^{24}$ Erythrocyte ghosts were obtained according to Dodge et al. ${ }^{25}$

\section{Microscopic Investigation}

For investigation with the optical microscope, the red cells, when separated from plasma, were washed four times in saline solution and suspended in the same solution but containing 0.01 or $0.1 \mathrm{mg} / \mathrm{ml}$ of the phenolic extracts studied. Hematocrit of the erythrocytes in the modification solution was $2 \%$, the modification lasting $1 \mathrm{~h}$ at $37{ }^{\circ} \mathrm{C}$. After modification, the erythrocytes were fixed with $0.2 \%$ solution of glutaraldehyde. After that, the red cells were observed under a biological optical microscope Nikon Eclipse E200 equipped with a digital camera. The photographs obtained made it possible to count erythrocytes of various shapes, and then the percent share of two basic forms (echinocytes and stomatocytes) in a population of ca. 800 cells were determined. The individual forms of erythrocyte cells were ascribed morphological indices according to Bessis' scale, ${ }^{26,27}$ which for stomatocytes assume negative values from -1 to -4 , and for echinocytes from 1 to 4 .

For investigation with electron microscope, the red cells, when separated from plasma, were washed four times in saline solution and suspended in the same solution but containing $0.1 \mathrm{mg} / \mathrm{ml}$ of the extracts studied. Hematocrit of the erythrocytes in the modification solution was $2 \%$, the modification lasting $1 \mathrm{~h}$ at $37{ }^{\circ} \mathrm{C}$. After modification the erythrocytes were fixed for $12 \mathrm{~h}$ in $2.5 \%$ solution of glutaraldehyde buffered with PBS of pH 7.4 at $18{ }^{\circ} \mathrm{C}$. After the fixation the material was fixed again for $1 \mathrm{~h}$ in $1 \%$ solution of osmium quatroxide in the same buffer at $4{ }^{\circ} \mathrm{C}$. Mika slates covered with the red cells were dehydrated with solutions of alcohol and acetone of increasing concentrations. The preparations were then dried with a method based on the critical point of $\mathrm{CO}_{2}$ in a Balzer's instrument CP-010. Afterwards, mika fragments covered with cells were placed on metal plates and sprayed with carbon and 
Table 1 Contents of phenolic compounds $\left(\mathrm{g} / \mathrm{kg}^{-1}\right)$ in strawberry, chokeberry, and apple extracts

\begin{tabular}{|c|c|c|c|}
\hline Phenolic compound & Strawberry & Chokeberry & Apple \\
\hline Pelargonidin-3-rutinoside & 2.33 & 0 & 0 \\
\hline Pelargonidin-3-glucoside & 45.32 & 0 & 0 \\
\hline Pelargonidin-3glucoside-malonyl & 2.76 & 0 & 0 \\
\hline Cyanidin-3-galactoside & 0 & 15.53 & 0.12 \\
\hline Cyanidin-3-arabinoside & 0 & 6.17 & 0 \\
\hline Cyanidin-3-xyloside & 0 & 1.03 & 0 \\
\hline Cyanidin-3-glucoside & 1.97 & 0.79 & 0 \\
\hline Chlorogenic.acid & 0 & 6.24 & 16.67 \\
\hline Neochlorogenic.acid & 0 & 6.03 & 0 \\
\hline$p$-coumaroyl-glucoside & 3.12 & 0 & 1.56 \\
\hline Ellagic acid & 2.97 & 0 & 0 \\
\hline$(+)$-catechin & 2.69 & 0 & 0.7 \\
\hline$(-)$-epicatechin & 0 & 1.95 & 4.32 \\
\hline Procyanidins B2 & 0 & 0 & 2.43 \\
\hline Procyanidins B3 & 2.55 & 0 & 0 \\
\hline Procyanidins $\mathrm{C} 1$ & 0 & 0 & 1.63 \\
\hline Polimeric procyanidins & 7.94 & 14.90 & 17.00 \\
\hline Phloretin-2'-O-xyloglucoside & 0 & 0 & 0.72 \\
\hline Phloretin-2-O'-glucoside & 0 & 0 & 9.13 \\
\hline Quercetin-3-O-galactoside & 0 & 2.83 & 0.84 \\
\hline Quercetin-3-O-glucoside & 2.84 & 2.25 & 0.12 \\
\hline Quercetin-3-O-arabinoside & 0 & 0 & 0.41 \\
\hline Quercetin-3-O-xyloside & 0 & 0 & 0.94 \\
\hline Quercetin-3-O-rutinoside & 0 & 1.68 & 0 \\
\hline Quercetin-3-O-vicianoside & 0 & 1.15 & 0 \\
\hline Quercetin-3- O-robinobioside & 0 & 1.17 & 0 \\
\hline Keampferol-3-O-glucoside & 0.55 & 0 & 0 \\
\hline Eriodictyol-3,7- O-diglucuronide & 0 & 1.86 & 0 \\
\hline TOTAL & 75.04 & 63.58 & 56.59 \\
\hline
\end{tabular}

silver in a sputter VEB Hochvakuum-Dresden B30.1. The preparations were watched and photographed in a scanning electron microscope Tesla BS 300 at $20 \mathrm{kV}$.

\section{Fluorimetric Method}

The effect of polyphenols on the packing order of lipids in the erythrocyte membrane (ghosts) and model lipid membrane were investigated using the fluorimetric method. Fluorescence intensity was measured by using fluorescent probes: laurdan, DPH, and TMA-DPH. These fluorescent probes were used because each of them embeds itself in different regions of the lipid bilayer. The TMA-DPH probe incorporates at the fourth carbon atom in the transient region between hydrophobic and hydrophilic parts of the bilayer. The DPH and laurdan probes locate in the hydrophobic and hydrophilic regions of the bilayer, respectively. Such differentiated incorporation of the probes gives insight into the structural changes caused by incorporation of polyphenols of fruit extracts. ${ }^{28,29}$
The ghosts were suspended in an isotonic phosphate solution of $\mathrm{pH}$ 7.4, of such quantity that the protein concentration in the samples amounted to approximately $100 \mathrm{mg} / \mathrm{ml}$. Control samples contained an erythrocyte ghost suspension and a fluorescent probe, while the investigated samples contained in addition proper concentrations of the compounds studied. Fluorescence intensity was measured by using three fluorescent probes: laurdan, DPH, and TMA$\mathrm{DPH}$ whose concentration in the samples was $10 \mu \mathrm{M}$, while concentrations of the compounds were within the range $0.005-0.05 \mathrm{mg} / \mathrm{ml}$ at temperature $37^{\circ} \mathrm{C}$. The measurements were conducted with a fluorimeter CARRY Eclipse of VARIAN equipped with a Peltier temperature controller DBS (temperature accuracy $\pm 0.1{ }^{\circ} \mathrm{C}$ ). The excitation and emission wavelengths were: for probe DPH: $\lambda_{\mathrm{ex}}=360 \mathrm{~nm}$, $\lambda_{\mathrm{em}}=425 \mathrm{~nm}$ and for probe TMA-DPH: $\lambda_{\mathrm{ex}}=358 \mathrm{~nm}$, $\lambda_{\mathrm{em}}=428 \mathrm{~nm}$. The excitation wavelength for Laurdan was $360 \mathrm{~nm}$, and the emitted fluorescence was recorded at two wavelengths 440 and $490 \mathrm{~nm}$. 

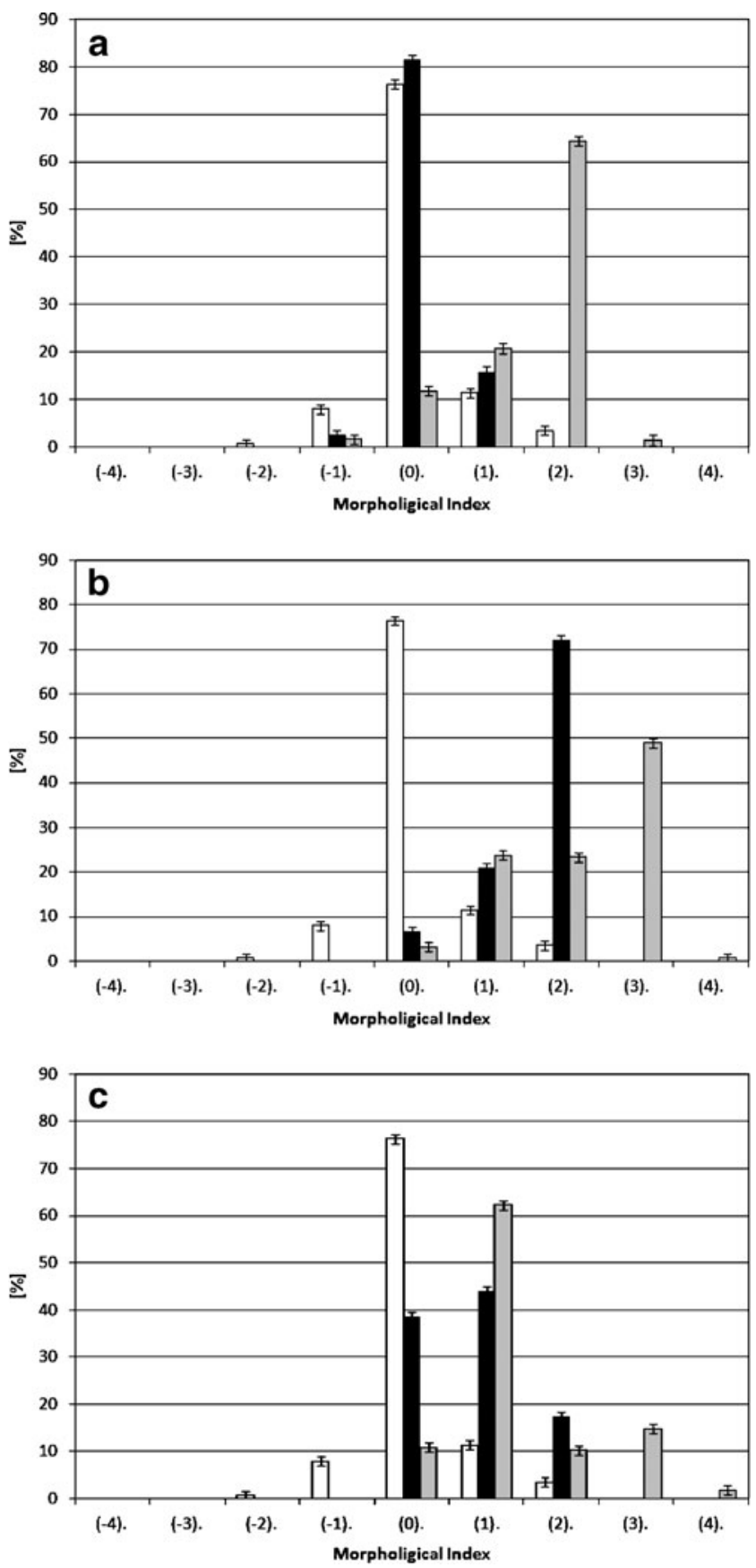

Fig. 1 Percent share of different shapes of erythrocytes induced by extracts from apple (a), chokeberry (b), and strawberry (c) at 0.1 (gray bar) and 0.01 (black bar) $\mathrm{mg} / \mathrm{ml}$ concentration, control (white bar). On the abscissa there are morphological indices for the respective shapes of cells: spherostomatocytes $(-4)$, stomatocytes II $(-3)$, stomatocytes I ( -2$)$, discostomatocytes $(-1)$, discocytes $(0)$, discoechinocytes (1), echinocytes (2), spheroechinocytes (3), and spherocytes (4)

Monolayer liposomes were formed from phosphatidylcholine (DPPC, egg-PC). The lipids were dissolved in chloroform, and a suitable probe was added and very carefully evaporated to dryness under nitrogen. Then, to the film obtained, phosphate buffer of $\mathrm{pH} 7.4$ was added and multilayer liposomes were formed by mechanical shaking at DPPC phase transition. Monolayer liposomes were obtained using an extruder. Control samples contained lipid suspension and a suitable fluorescence probe at 100:1 M ratio, a proper compound of concentration $0.005-0.05 \mathrm{mg} /$ $\mathrm{ml}$ being added to the remaining samples. Fluorescence intensity was measured with the laurdan and DPH probes. ${ }^{30}$ The measurements were made at various temperatures, above and below the main DPPC transition.

Multilamellar liposomes were formed from natural lipids extract from erythrocytes membrane. The natural lipids were dissolved in a chloroform/methanol solvent, next, evaporated to dryness under nitrogen. Then, to the film obtained, phosphate buffer of $\mathrm{pH} 7.4$ was added and liposomes were formed by sonification in the presence of fluorescent probes at 1000:1 ratio (lipids/fluorescent probes). Control samples contained only lipid suspension with a fluorescence probe, a proper compound at concentration $0.005-0.05 \mathrm{mg} / \mathrm{ml}$ being added to the remaining samples. Fluorescence intensity was measured with laurdan and DPH probes. $^{31}$

Fluorescence anisotropy $(A)$ for probes DPH and TMADPH was calculated using the formula ${ }^{30}$ :

$A=\frac{\left(I_{\mathrm{II}}-G I_{\perp}\right)}{\left(I_{\mathrm{II}}+2 G I_{\perp}\right)}$

where $\mathrm{I}_{\mathrm{II}}$ and $\mathrm{I}_{\perp}$ are the fluorescence intensities observed in directions parallel and perpendicular, respectively, with respect to the polarization direction of the exciting wave. $G$ is an apparatus constant dependent on the emission wavelength.

Changes in the packing order of the hydrophilic part of the membrane were investigated using the laurdan probe, on the basis of generalized polarization (GP), and were calculated with the formula ${ }^{32}$ :

$G P=\frac{\left(I_{\mathrm{b}}-I_{\mathrm{r}}\right)}{\left(I_{\mathrm{b}}+I_{\mathrm{r}}\right)}$

where $I_{\mathrm{b}}$ is the fluorescence intensity at $\lambda=440 \mathrm{~nm}, I_{\mathrm{r}}$ is the fluorescence intensity at $\lambda=490 \mathrm{~nm}$.

\section{Calorimetric Studies}

In the calorimetric studies, the effect of the polyphenols on the pretransition $\left(T_{\mathrm{p}}\right)$ and main-transition $\left(T_{\mathrm{m}}\right)$ temperature of DPPC was analyzed. For that purpose, the differential scanning calorimetry (DSC) was used. The measurements were made with a calorimeter of Mettler Toledo Thermal Analysis System D.S.C. $821^{\mathrm{e}}$ (scanning rate $2{ }^{\circ} \mathrm{C} / \mathrm{min}$ ). The samples contained multilamellar liposomes formed of 1,2dipalmitoyl-sn-glycero-3-phosphatidylcholine (DPPC) in 

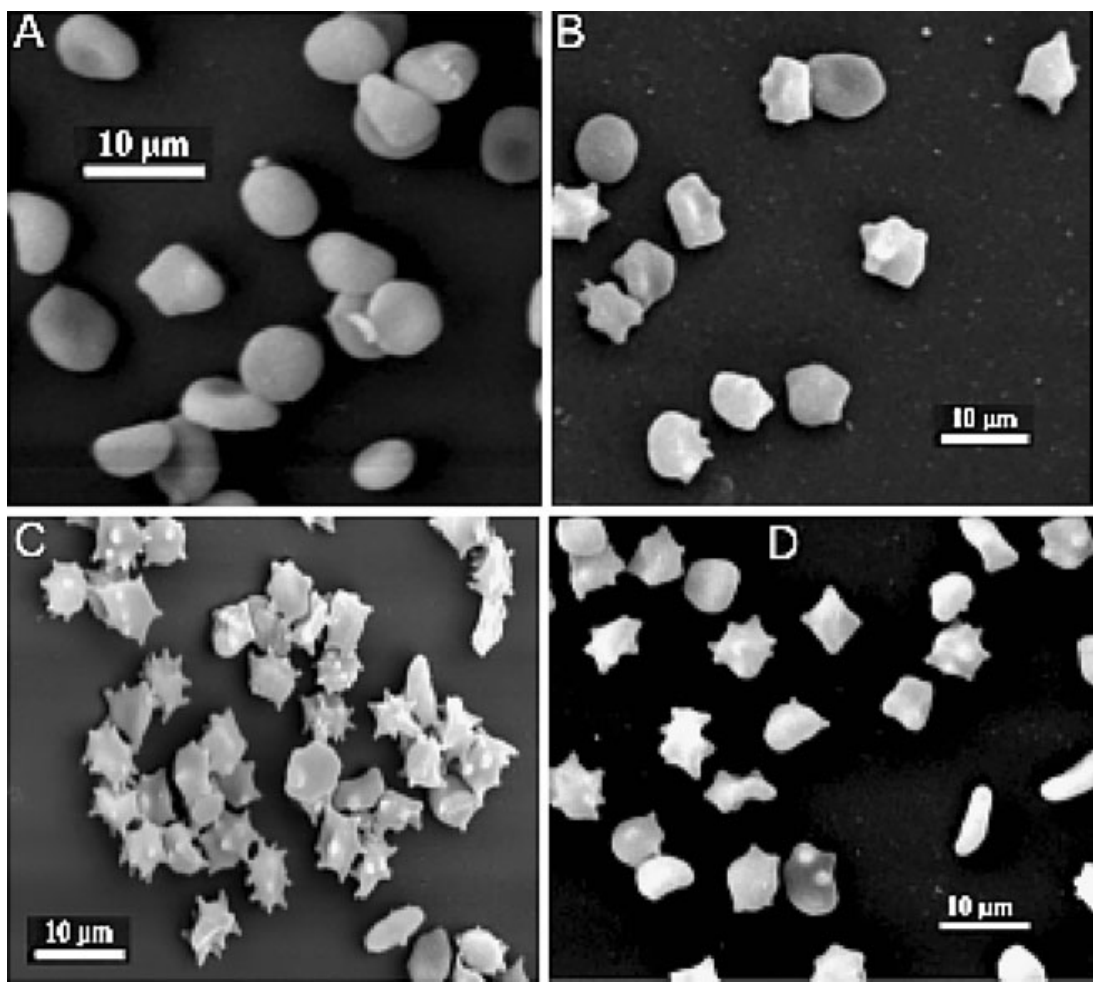

Fig. 2 Shapes of unmodified erytrocytes (a) and modyfied with extracts from apple (b), chokeberry (c), and strawberry (d), observed with electron microscope, at $0.1 \mathrm{mg} / \mathrm{ml}$ concentration

the presence of the fruit extracts. DPPC was dissolved in chloroform and then evaporated for ca. $2 \mathrm{~h}$ under nitrogen to dryness. The obtained film was admixed with fruit extracts solved in phosphate buffer of $\mathrm{pH} 7.4$ and liposomes were formed by mechanical shaking at temperature above the DPPC main phase transition. The lipid concentration in the samples was $25 \mathrm{mg} / \mathrm{ml}$. The prepared dispersion of pure lecithin (control sample) and lecithin with the compounds added were encapsulated in $40-\mu \mathrm{l}$ volumes and left for $24 \mathrm{~h}$ at $4{ }^{\circ} \mathrm{C}$ before measurement.

Statistical analysis was carried out using Statistica 8.0. (StatSoft Inc.). All experiments were performed at least in triplicate unless specified otherwise. Analysis of variance was carried out and significance between means was determined using Dunnett's post hoc test. Results are presented as mean \pm SD. Significant levels were defined at $p<0.05$.

\section{Results and Discussion}

\section{Microscopic Studies}

Figure 1 shows the percent share of the various forms of cells in a population of erythrocytes modified with extracts from apple, chokeberry, and strawberry at 0.1 and $0.01 \mathrm{mg} / \mathrm{ml}$ concentration. As seen in the figures, all the extracts induce mostly various forms of echinocytes, whose percent share in
Table 2 Values of fluorescence anisotropy $(A)$ of probe DPH in liposomes formed of lipids extracted from erythrocyte membranes and modified by apple, chokeberry, and strawberry extracts of various concentrations at $37^{\circ} \mathrm{C}$
Anisotropy $(A) \mathrm{DPH}$

\begin{tabular}{lccc}
\hline $\begin{array}{l}\text { Extract } \\
\text { Concentrations }[\mathrm{mg} / \mathrm{ml}]\end{array}$ & $\begin{array}{l}\text { Apple } \\
\text { Anisotropy }(A) \pm \mathrm{SD}\end{array}$ & $\begin{array}{l}\text { Chokeberry } \\
\text { Anisotropy }(A) \pm \mathrm{SD}\end{array}$ & $\begin{array}{l}\text { Strawberry } \\
\text { Anisotropy }(A) \pm \mathrm{SD}\end{array}$ \\
\hline Control & $0.226 \pm 0.003$ & $0.226 \pm 0.003$ & $0.226 \pm 0.003$ \\
0.0050 & $0.218 \pm 0.001$ & $0.225 \pm 0.002$ & $0.228 \pm 0.004$ \\
0.0075 & $0.217 \pm 0.001$ & $0.215 \pm 0.002$ & $0.217 \pm 0.002$ \\
0.0100 & $0.214 \pm 0.002$ & $0.214 \pm 0.001$ & $0.215 \pm 0.003$ \\
0.0250 & $0.212 \pm 0.003$ & $0.213 \pm 0.003$ & $0.212 \pm 0.002$ \\
0.0500 & $0.214 \pm 0.001$ & $0.210 \pm 0.002$ & $0.210 \pm 0.002$ \\
\hline
\end{tabular}




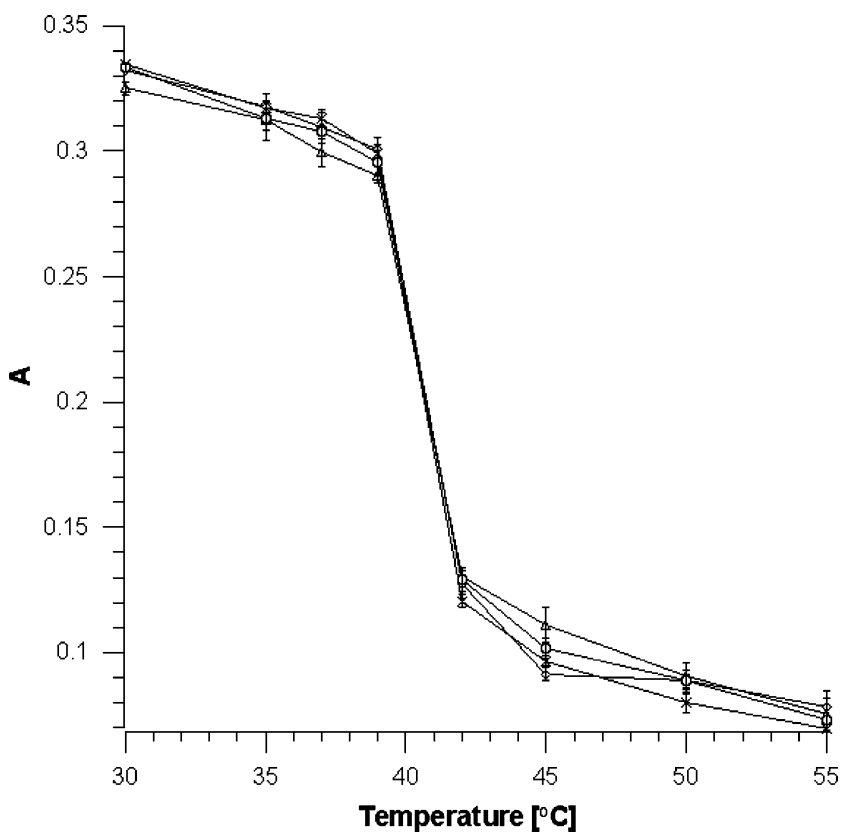

Fig. 3 Values of fluorescence anisotropy (a) at different temperatures and selected extract concentration $(0.05 \mathrm{mg} / \mathrm{ml})$. Legend X-DPPC, (white circle) apple extract, (diamond) chokeberry extract, (white triangle) strawberry extract

a population depends on the type of compound. Chokeberry is responsible for creation of the most varied forms of echinocytes. It can thus be assumed that the extracts concentrate mainly in the outer monolayer of the erythrocyte membrane when inducing echinocytes, and practically do not permeate into the inner monolayer of the membrane. ${ }^{11,33-35}$

Proportions of the different populations of red cells, identified by optical microscopy using Bessis's morphological index, are presented in Figure 1 for all three pholyphenolic extracts at both concentrations.

Figure 2 shows the erythrocyte shapes as observed in scanning electron microscopy. All extracts induced mostly formation of various forms of echinocytes, the proportions of which depended on the phenolic extract used. Chokeberry was responsible for creation of the most varied forms of echinocytes (Figure 2c).

Studies of Iglic et al. ${ }^{33}$ and Isomaa et al. ${ }^{35}$ have shown that formation of echinocytes occurred when amphiphilic molecules were incorporated in the outer monolayer of the erythrocyte membrane. Compounds penetrating to the inner monolayer of the membrane induced formation of stomatocytes. We can therefore assume that the polyphenols in the apple, chokeberry, and strawberry extract concentrated mainly in the outer monolayer of the erythrocyte membrane.

\section{Fluorimetric Measurements}

The effect of extracts from apple, chokeberry, and strawberry on fluidity of the lipid phase of erythrocyte and liposome membranes was studied on the basis of fluorescence anisotropy measured with the two fluorescence probes DPH and TMA-DPH. An investigation was also conducted of lipid fluidity in the hydrophobic region of the liposome membrane formed of lipids extracted from erythrocyte membranes. The results on the DPH probe fluorescence anisotropy for such a membrane are presented in Table 2. These results indicate at minor changes caused by the extracts in the hydrocarbon chains of membrane lipids, testifying that the extract phenols do not penetrate deep into the lipid hydrophobic region.

As indicated by the values of fluorescence anisotropy at the interphase between the hydrophilic and hydrophobic parts of membrane - the area were the probes TMA-DPH incorporate, the extracts practically have no effect on the fluidity of the lipid layer. A lack of changes for apple, and a small increase in fluidity for chokeberry and strawberry are observed in the hydrophobic region where the unspecific probe DPH locates. It can thus be postulated that the compounds within the extracts practically do not concentrate in the hydrophobic lipid phase of the erythrocyte membrane. ${ }^{4,5}$

Using the DPH probe, it was checked how the fluidity of the model membrane modified with polyphenols in the extracts at various temperature changes. In the area of hydrocarbon chains, no effect of the extracts was observed in the range of the main phase transition of DPPC. The presence of the compounds only slightly increases the fluorescence anisotropy of the liquid-crystal phase (Figure 3).

We also investigated the degree of order in the hydrophilic part of liposomes formed of lipids extracted from erythrocyte membranes by using the laurdan probe. The calculated values of GP (Table 3) decrease with increasing extract concentration, which is indicative of
Table 3 Values of GP of the laurdan probe in liposomes formed of lipids extracted from erythrocyte membranes, subjected to the action of different concentrations of extracts from apple, chokeberry, and strawberry at $37^{\circ} \mathrm{C}$

\begin{tabular}{llllll}
\hline $\begin{array}{l}\text { Concentration }[\mathrm{mg} / \mathrm{ml}] \\
\text { Extract }\end{array}$ & 0.0050 & 0.0075 & 0.0100 & 0.0250 & 0.0500 \\
\hline Apple & $0.285 \pm 0.003$ & $0.281 \pm 0.003$ & $0.281 \pm 0.001$ & $0.276 \pm 0.005$ & $0.267 \pm 0.005$ \\
Chokeberry & $0.284 \pm 0.001$ & $0.284 \pm 0.004$ & $0.284 \pm 0.005$ & $0.277 \pm 0.009$ & $0.269 \pm 0.008$ \\
Strawberry & $0.284 \pm 0.003$ & $0.283 \pm 0.009$ & $0.282 \pm 0.006$ & $0.281 \pm 0.004$ & $0.271 \pm 0.008$ \\
Control & $0.286 \pm 0.004$ & & & & \\
\hline
\end{tabular}


Table 4 Values of fluorescence anisotropy $(A)$ of the probes DPH, TMA-DPH, and values of GP of the laurdan

fluorescence probe, obtained for erythrocyte ghosts modified with different concentrations extracts from apple, chokeberry, and strawberry at $37^{\circ} \mathrm{C}$

\begin{tabular}{llll}
\hline $\begin{array}{l}\text { Probes } \\
\text { Concentrations }[\mathrm{mg} / \mathrm{ml}]\end{array}$ & $\begin{array}{l}\text { DPH } \\
\text { Anisotropy }(A) \pm \mathrm{SD}\end{array}$ & $\begin{array}{l}\text { TMA-DPH } \\
\text { Anisotropy }(A) \pm \mathrm{SD}\end{array}$ & $\begin{array}{l}\text { Laurdan } \\
\text { General polarization }(\mathrm{GP}) \pm \mathrm{SD}\end{array}$ \\
\hline Apple & & & \\
Control & $0.239 \pm 0.002$ & $0.268 \pm 0.001$ & $0.442 \pm 0.009$ \\
0.0050 & $0.233 \pm 0.002$ & $0.264 \pm 0.001$ & $0.368 \pm 0.007$ \\
0.0075 & $0.235 \pm 0.003$ & $0.266 \pm 0.004$ & $0.341 \pm 0.007$ \\
0.0100 & $0.233 \pm 0.001$ & $0.260 \pm 0.004$ & $0.323 \pm 0.006$ \\
0.0250 & $0.232 \pm 0.004$ & $0.264 \pm 0.005$ & $0.234 \pm 0.005$ \\
0.0500 & $0.230 \pm 0.002$ & $0.264 \pm 0.003$ & $0.158 \pm 0.003$ \\
Chokeberry & & & $0.442 \pm 0.009$ \\
Control & $0.239 \pm 0.002$ & $0.268 \pm 0.001$ & $0.406 \pm 0.008$ \\
0.0050 & $0.231 \pm 0.002$ & $0.270 \pm 0.003$ & $0.386 \pm 0.008$ \\
0.0075 & $0.233 \pm 0.008$ & $0.268 \pm 0.003$ & $0.399 \pm 0.008$ \\
0.0100 & $0.227 \pm 0.003$ & $0.269 \pm 0.002$ & $0.332 \pm 0.007$ \\
0.0250 & $0.227 \pm 0.006$ & $0.271 \pm 0.006$ & $0.210 \pm 0.004$ \\
0.0500 & $0.224 \pm 0.004$ & $0.268 \pm 0.006$ & \\
Strawberry & & & $0.442 \pm 0.009$ \\
Control & $0.239 \pm 0.002$ & $0.268 \pm 0.001$ & $0.391 \pm 0.008$ \\
0.0050 & $0.229 \pm 0.005$ & $0.267 \pm 0.005$ & $0.387 \pm 0.008$ \\
0.0075 & $0.230 \pm 0.012$ & $0.267 \pm 0.001$ & $0.376 \pm 0.008$ \\
0.0100 & $0.226 \pm 0.004$ & $0.265 \pm 0.002$ & $0.324 \pm 0.006$ \\
0.0250 & $0.225 \pm 0.005$ & $0.263 \pm 0.003$ & 0.004 \\
0.0500 & $0.220 \pm 0.006$ & $0.262 \pm 0.005$ & \\
\hline
\end{tabular}

increasing disorder in the hydrophilic part of the lipid layer and the presence of the compounds in that area. Though the changes induced by the extracts in liposome membranes are smaller than those in erythrocyte membranes, the conviction remains that the polyphenolic compounds in the extracts incorporate into erythrocyte and liposome membranes, concentrating mainly in their hydrophilic part.

The investigation of the lipid phase packing order in the hydrophilic region of the erythrocyte membrane, using the laurdan probe, showed distinct changes induced by the extracts. The determined values of GP decreased significantly with increasing concentration of the extracts, which indicate an increasing disorder of the polar heads of membrane lipids induced by incorporation of the polyphenolic compounds contained in the extracts. The most effective in inducing disorder in the hydrophilic region of the erythrocyte membrane is the apple extract, the GP value decreasing threefold with the highest concentration used $0.05 \mathrm{mg} / \mathrm{ml}$. Thus, it can be inferred that the fruit extracts phenols incorporate and concentrate mainly in the hydrophilic region of the membrane (Table 4). ${ }^{30,32}$

By using the laurdan probe we investiged the packing order of the hydrophilic phase of the model membrane formed of egg-PC. The measurements were carried out at constant temperature of $37{ }^{\circ} \mathrm{C}$, and the results, for a selected concentration $(0.05 \mathrm{mg} / \mathrm{ml})$. In the presence of extracts the value of the GP coefficient increases,

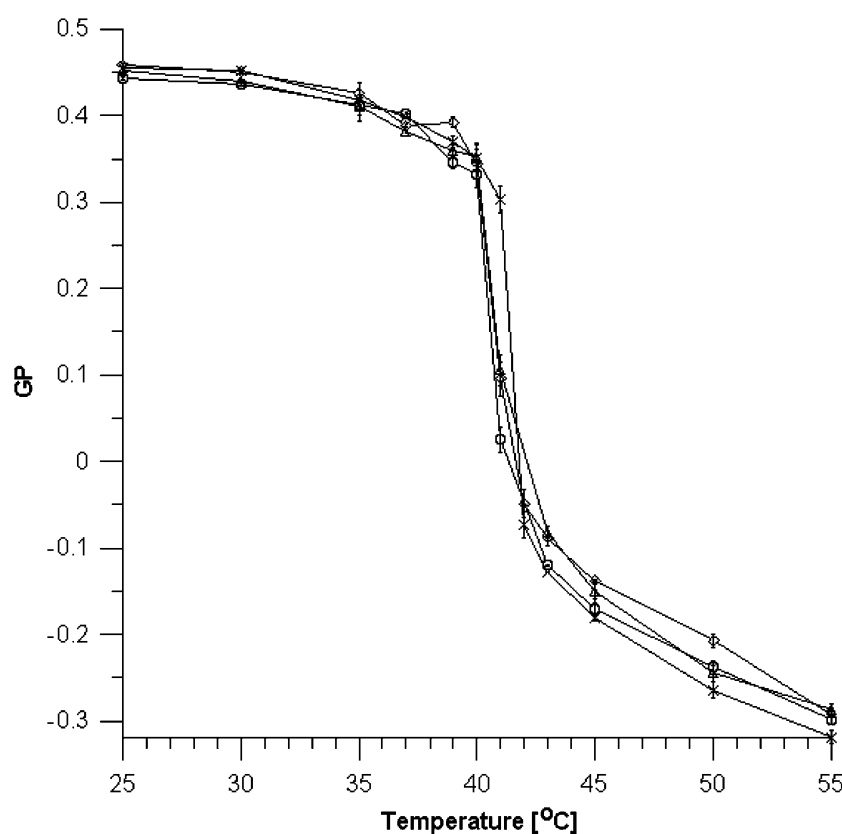

Fig. 4 GP coefficient of a laurdan probe vs. temperature for a selected extract concentration of $0.05 \mathrm{mg} / \mathrm{ml}$. Legend X-DPPC, (white circle) apple extract, (diamond) chokeberry extract, (white triangle) strawberry extract 


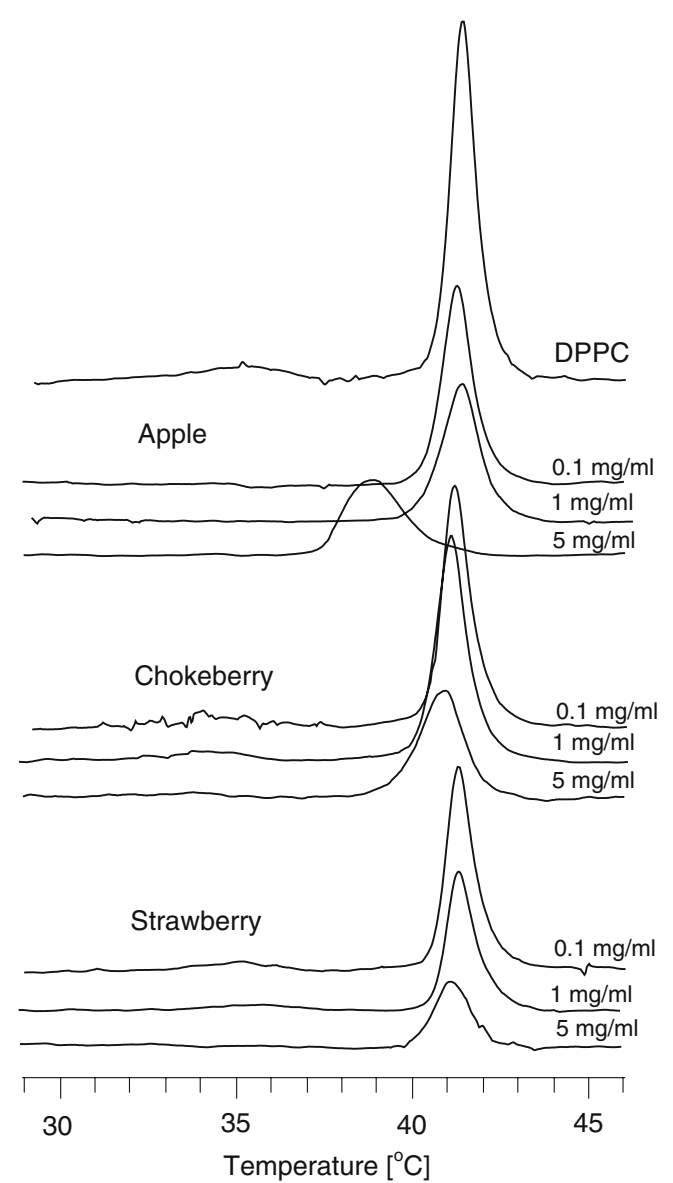

Fig. 5 Calorimetric curves of DPPC liposomes in the presence of extracts from the fruits of apple, chokeberry, and strawberry

relative to control $(\mathrm{GP}=-0.251 \pm 0.005)$, which is indicative of increased packing density in the polar region of the lipid membrane. We also observed a substantial decrease in fluorescence intensity for the extract modified samples, which is indicative of membrane dehydration induced by the incorporated polyphenols: chokeberry extract $(\mathrm{GP}=-0.179 \pm 0.001)$, strawberry extract $(\mathrm{GP}=-0.205 \pm 0.041)$. The largest decrease in intensity was found for the apple extract (GP $=-0.168 \pm 0.004)$, which is thought to modify the liposome membrane most.

The effect of the polyphenols in the extracts on the temperature of the main phase transition of the DPPC found by the fluorimetric method using the laurdan probe was also studied. From the fluorimetric spectra, GP values were calculated and presented in Figure 4 for different temperatures.

The presence of the extracts changes the main phase transition temperature slightly, though greater changes were observed in the value of GP for the liquid-crystal phase (Figure 4).

\section{Calorimetric Studies}

The calorimetric studies investigated the effect of the plant polyphenols on the temperature of the phase pretransition $\left(T_{\mathrm{p}}\right)$ and temperature of the main phase transition $\left(T_{\mathrm{m}}\right)$ of phosphatidylcholine. The measurements were made for a number of chosen concentrations of the extracts within the range $0.1-5.0 \mathrm{mg} / \mathrm{ml}$ (Figure 5). With increasing concentration, the polyphenols caused a slight decrease in the phase transition temperature $\left(T_{\mathrm{m}}\right)$ and increase in the peak half-width. The changes were greatest for the apple extract (Table 5). Polyphenols contained in this extract affected the lipid phase most, compared with the others. They removed the pretransition at the lowest concentration, lowered the main-transition temperature more than the others, and diminished cooperativity of that transition.

\section{Conclusions}

The results of the presented research have shown that extracts from apple, chokeberry, and strawberry induce changes in biological and model lipid membranes. The extracts contain various polyphenols of amphiphilic character (Table 1), which can interact with the biological membrane in its different phases. The most effective in bringing about changes is the apple extract. When analyzing the phenolic composition of the apple extract, it is evident that an important role can be attributed to the dominant chlorogenic acid. The interaction of the acid with the biological membrane has become for us an inspiration to further studies.

Various membrane models were used in the experiment, from the simple one-lipid DPPC membrane, thorough more complicated membranes of liposomes formed of a mixture egg-PC plus lipids extracted from erythrocytes, up to the most complicated model membrane which is the erythrocyte ghost. The ghosts contain, aside from lipids, proteins,
Table 5 Temperatures of the main phase transition and halfwidths for DPPC liposomes modified with fruit extracts. Accuracy of temperature measurement: $\pm 0.2{ }^{\circ} \mathrm{C}$

\begin{tabular}{|c|c|c|c|c|c|c|c|c|}
\hline \multirow[t]{2}{*}{ Concentration $\mathrm{mg} / \mathrm{ml}$} & \multicolumn{2}{|c|}{ Apple } & \multicolumn{2}{|c|}{ Chokeberry } & \multicolumn{2}{|c|}{ Strawberry } & \multicolumn{2}{|c|}{ DPPC } \\
\hline & $T_{\mathrm{m}}$ & $T_{1 / 2}$ & $T_{\mathrm{m}}$ & $T_{1 / 2}$ & $T_{\mathrm{m}}$ & $T_{1 / 2}$ & $T_{\mathrm{m}}$ & $T_{1 / 2}$ \\
\hline 0.1 & 41.2 & 1.0 & 41.2 & 0.9 & 41.2 & 0.9 & \multirow[t]{3}{*}{41.3} & \multirow[t]{3}{*}{0.9} \\
\hline 1 & 41.1 & 1.2 & 40.9 & 0.9 & 41.3 & 0.9 & & \\
\hline 5 & 38.6 & 2.0 & 40.8 & 1.4 & 41.1 & 1.2 & & \\
\hline
\end{tabular}


sugars, and their derivatives. Individual fruit extracts when interacting with particular model membranes indicate at membrane changes of the same character.

The fruits extracts caused small biophysical perturbations in model membranes. The evidence was derived from the steady-state anisotropy results performed with DPH and TMA-DPH fluorescent probes, which are located at different depths in the membrane. Very small changes in anisotropy value of DPH in all the models of the membranes occurred. This could mean that the extracts do not have lipophilic character. Also, changes in anisotropy value reported by the TMA-DPH probes indicated few modifications of the erythrocyte membrane. The lack of essential changes with respect to control in this interphase region could mean that the extracts incorporated into the membrane quite shallowly. ${ }^{4,5,14,16,36}$

This conclusion is confirmed by the fluorimetric studies with the laurdan probe. An important decrease in generalized polarization was observed with all three polyphenolic extracts at different concentrations in all the membranes tested. Laurdan is a fluorescent probe that locates in the phospholipids glycerol backbone and is sensitive to polarity changes and dynamic properties at membrane's lipid-water interface. The probe emission spectrum goes from blue, when the chromophore local environment is less polar, shift to a red shift as the polarity increases. ${ }^{28-32}$ Laurdan emission spectral shifts also happen when the membrane changes from gel to lipid-cristaline phase due to dipolar relaxation processes of the water molecules surrounding the laurdan chromophore, which is closely related with dynamic and free movement of the water molecules. ${ }^{32}$ Decreased GP values (the most by the apple extract) in the tested membranes seemed to indicate increased lipid-water interface hydration that is leading to the laurdan spectral red shift.

The polyphenol extracts had little impact on the phase transition temperature, as seen by DSC or in generalized polarization studied at different temperatures with DPPC liposomes. ${ }^{17,37}$

Polyphenolic extracts induced a modification of the shape of erythrocytes towards echinocytes, indicative of modifications in the surface of the cell membrane.

All the experimental results show that the changes are greatest in the hydrophilic part of erythrocyte membranes and lipid membranes formed of natural lipids, extracted from erythrocytes and phosphatidylcholine lipids. The phenolic compounds incorporated mainly into the outer, hydrophilic part of the membranes. They had practically no influence on fluidity in the hydrophobic region of the membranes, i.e., in the area of their hydrocarbon chains. On the basis of the results obtained, one can infer that the protective action of polyphenolic compounds with respect to biological membranes depends on the extent of their incorporation in the hydrophilic part of membrane.
The location of the extracts in the hydrophilic part of membrane seem to constitute a protective shield of the cell against other substances, the reactive forms of oxygen in particular, which finds its reflection in their antioxidant properties.

Open Access This article is distributed under the terms of the Creative Commons Attribution Noncommercial License which permits any noncommercial use, distribution, and reproduction in any medium, provided the original author(s) and source are credited.

\section{References}

1. C.A. Rice-Evans, N.J. Miller, G. Pganga, Antioxidant properties of phenolic compounds. Trends Plant Sci 2(4), 152-159 (1997)

2. A. Wojdyło, J. Oszmiański, R. Czemerys, Antioxidant activity and phenolic compounds in 32 selected herbs. Food Chem 105, 940 949 (2007)

3. B. Bukowska, J. Michałowicz, A. Krokosz, P. Sicińska, Comparison of the effect of phenol and its derivatives on protein and free radical formation in human erythrocytes (in vitro). Blood Cells Mol Dis 39, 238-244 (2007)

4. M. Suwalsky, P. Orellana, M. Avello, F. Villena, C.P. Sotomayor, Human erythrocytes are affected in vitro by extracts of Ugni molinae leaves. Food Chem Toxicol 44, 1393-1398 (2006)

5. M. Suwalsky, K. Oyarce, M. Avello, F. Villena, C.P. Sotomayor, Human erythrocytes an molecular modelas of cell membranes are affected in vitro by Balbisia peduncularis (Amancay) extracts. Chem-Biol Interact 179, 413-418 (2009)

6. S. Kondo, K. Tsuda, N. Muto, J. Ueda, Antioxidative activity of apple skin or flesh extracts associated with fruit development on selected apple cultivars. Scientia Horticulturae 96, 177-185 (2002)

7. S. Kondo, H. Yoshikawa, N. Miwa, Cytoprotective effect of fruit extracts associated with antioxidant activity against ultraviolet rays. Food Chem 104, 1272-1276 (2007)

8. A. Matkowski, S. Zielińska, J. Oszmiański, E. Lamer-Zarawska, Antioxidant activity of extracts from leaves and roots of Salvia miltiorrhiza Bunge. S. przewalskii Maxim., and S. verticillata L. Bioresour Technol 99, 7892-7896 (2008)

9. J. Oszmiański, M. Wolniak, A. Wojdyło, I. Wawer, Influence of apple purée preparation and storage on polyphenol contents and antioxidant activity. Food Chem 107, 1473-1484 (2008)

10. J. Oszmiański, A. Wojdyło, Aronia melanocarpa phenolics and their antioxidant activity. Eur Food Res Technol 221, 809-813 (2005)

11. T. Pajk, V. Rezar, A. Levart, J. Salobir, Efficiency of apples, strawberries, and tomatoes for reduction of oxidative stress in pigs as a model for human. Nutrition 22, 376-384 (2008)

12. K. Skupień, J. Oszmiański, Comparison of six cultivars of strawberries (Fragaria $x$ ananassa Duch.) grown in northwest Poland. Eur Food Res Technol 219, 66-70 (2004)

13. S. Chaudhuri, A. Banerjee, K. Basu, B. Sengupta, P.K. Sengupta, Interaction of flavonoids with red blood cell membrane lipids and proteins: Antioxidant and antihemolytic effects. Int J Biol Macromol 41, 42-48 (2007)

14. B. Pawlikowska-Pawlęga, W.I. Gruszecki, L.E. Misiak, A. Gawron, The study of the quercetin action on human erythrocyte membranes. Biochem Pharmacol 66, 605-612 (2003) 
15. M. Suwalsky, P. Orellana, M. Avello, F. Villena, Protective effect of Ugni molinae Turcz against oxidative damage of humane erythrocyte. Food Chem Toxicol 45, 130-135 (2007)

16. M. Suwalsky, P. Vargas, M. Avello, F. Villena, C.P. Sotomayor, Human erythrocytes are affected on vitro by flavonoids of Aristotelia chilensis (Maqui) leaves. Int J Pharm 363, 85-90 (2008)

17. O. Wesołowska, M. Kużdżał, J. Štrancar, K. Michalak, Interaction of chemopreventive agent resveratrol and its metabolite. piceatannol with model membranes. Biochim Biophys Acta 1788, 1851-1860 (2009)

18. A. Arora, T.M. Byren, M.G. Nair, G.M. Strasburg, Modulation of liposomal membrane fluidity by flavonoids and isoflavonoids. Arch Biochem Biophys 373(1), 102-109 (2000)

19. S. Chaudhuri, P. Biswapathik, P.K. Sengupta, Ground and excited state proton transfer and antioxidant activity of 7-hydroxyflavone in model membranes: Absorption and fluorescence spectroscopic studies. Biophys Chem 139, 29-36 (2009)

20. K. Gąsiorowski, K. Szyba, B. Brokos, B. Kołaczyńska, M. Jankowiak-Włodarczyk, J. Oszmiański, Antimutagenic activity of anthocyanins isolated from Aronia melanocarpa fruits. Cancer Lett 119, 37-46 (1997)

21. I. Mudnic, D. Modun, I. Brizic, J. Vukovic, I. Generalic, V. Katalinic, T. Bilusic, I. Ljubenkov, M. Boban, Cardiovascular effect in vitro of aqueous extract of wild strawberry (Fragaria vesca. L.) leaves. Phytomedicine 16, 462-469 (2009)

22. M. Naruszewicz, I. Łaniewska, B. Millo, M. Dłużniewski, Combination therapy of statin with flavonoids rich extract from chokeberry fruits enhanced reduction in cardiovascular risk markers in patients after myocardial infraction (MI). Atherosclerosis 194, 179-184 (2007)

23. Z. Zduńczyk, S. Frejnagel, M. Wróblewska, J. Juśkiewicz, J. Oszmiański, I. Estrella, Biological activity of polyphenol extracts from different plant sources. Food Res Int 35, 183$186(2002)$

24. A.H. Maddy, M.J. Dunn, P.G. Kelly, The characterization of membrane proteins by centrifugation and gel electrophoresis. a comparison of proteins prepared by different methods. Biochim Biophys Acta 288, 263-278 (1972)

25. J.T. Dodge, C. Mitchell, D.J. Hanahan, The preparation and chemical characteristics of hemoglobin-free ghosts of erythrocytes. Arch Biochem 100, 119-130 (1963)
26. M. Bessis, La forme et la déformabilité des érythrocytes normaux et dans certaines anémies hémolytiques congénitales. Nouv Rev Fr Hématol 18, 75-94 (1977)

27. B. Deuticke, Transformation and restoration of biconcave shape of human erythrocytes induced by amphiphilic agents and changes of ionic environment. Biochim Biophys Acta 163, 494-500 (1968)

28. F.M. Harris, K.B. Best, J.D. Bell, Use of laurdan fluorescence intensity and polarization to distinguish between changes in membrane fluidity and phospholipid order. Biochim Biophys Acta 1565, 123-128 (2002)

29. D. Dumas, S. Muller, F. Gouin, F. Baros, M.-L. Viriot, J.F. Stoltz, Membrane fluidity and oxygen diffusion in choresterolenriched erythrocyte membrane. Arch Biochem Biophys 341, 34-39 (1997)

30. J.R. Lakowicz, Fluorescence Polarization, In: Principles of Fluorescence Spectroscopy (Plenum (London, New York, 1999), pp. $112-153$

31. L.A. Bagatolli, B. Maggio, F. Aguilar, C.P. Sotomayor, G.D. Fidelio, Laurdan properties in glycosphingolipid-phospholipid mixtures: a comparative fluorescence and calorimetric study. Biochim Biophys Acta 1325, 80-90 (1997)

32. T. Parasassi, E.K. Krasnowska, L. Bagatolli, E. Gratton, Laurdan and prodan as polarity-sensitive fluorescent membrane probes. J Fluoresc 8(4), 365-373 (1998)

33. A. Iglic, V. Kralj-Iglic, V.H. Hagerstand, Amphiphile induced echinocyte-spheroechinocyte transformation of red blood cell shape. Eur Biophys J 27, 335-339 (1998)

34. B. Isomaa, H. Hagerstrand, G. Paatero, Shape transformations induced by amphiphiles in erythrocytes. Biochim Biophys Acta 899, 93-103 (1987)

35. M.P. Sheetz, S.J. Singer, Biological membranes as bilayer couples. A molecular mechanism of drug-erythrocyte interactions. Proc Nat Acad Sci USA 71, 4457-4461 (1974)

36. L. Perez-Fons, M.T. Garzon, V. Micol, Relationship between the antioxidant capacity and effect of rosemary (Rosmarinus officinalis L.) polyphenols on membrane phospholipid order. J Agric Food Chem 58, 161-171 (2010)

37. V.A.O. Tiera, F.M. Winnik, M.J. Tiera, Interaction of amphiphilic derivatives of chitosan with DPPC (1, 2-dipalmitoyl-sn-glycero3phosphocholine). J Therm Anal Calorim 100, 309-313 (2010) 